\title{
Early Use of the Computer for Adjusting Triangulation in Iceland
}

\author{
Gunnar Thorbergsson \\ Formerly surveyor at Orkustofnun, Iceland \\ g@os.is
}

\begin{abstract}
Triangulation for long has been the backbone of land surveying and mapping. This work outlines its history in Iceland and provides an example of observations and computation in a triangulation network before the computer era came of age. The work describes briefly a computer program written in 1965 for the adjustment of observations in triangulation networks and mentions later improvements of the program.
\end{abstract}

Keywords: Iceland, surveying, triangulation, adjustment.

\section{Introduction}

People believe that the ancient Egyptians practiced land surveying, but triangulation, theodolites, and least squares adjustments are more recent. Willebrord Snellius (1580-1626) measured a network of 33 triangles early in the 17th century and the theodolite, an optical instrument for observing horizontal and vertical angles, was developed later in that century. Carl Friedrich Gauss (1777-1855) did triangulation work and invented the method of least squares.

Danish authorities had the coastal areas in Iceland surveyed and mapped in the beginning of the 19th century. Björn Gunnlaugsson (1788-1876), an Icelandic mathematician, surveyed and mapped the interior in the years 1831-1843. The Danish general staff started a new triangulation and mapping of Iceland in scale 1:100,000 in the year 1900. Geodætisk Institut concluded this work in 1939, while Iceland was still part of Denmark [3]. The governments of the United States, Denmark, and Iceland financed a first order triangulation of Iceland in 1955-56 [2]. See Figure 1.

Orkustofnun (National Energy Authority) started land surveying shortly before the middle of the 20th century. Extensive leveling networks were established and new triangulation networks were connected to the first order network from 1955-56. The National Land Survey of Iceland started aerial photography in 1955 and from that time, Orkustofnun used aerial photographs in its mapping projects. We established ground control for mapping in scale 1:20,000 with 5m contour intervals of large areas, and for maps in larger scale of smaller areas. We did this work for the purpose of hydropower development. Before the end of the century, we had surveyed about onethird of the country, mainly in its interior, and mapped a quarter of the country in this way; however we subcontracted the photogrammetry work to various Icelandic and Scandinavian engineering firms. 


\section{Adjustment before the Computer Era}

In the summer of 1962 surveyors at Orkustofnun did triangulation and leveling work at Búrfell where Landsvirkjun (The National Power Company) was going to build a hydro power plant. In the spring of 1963, the adjustment of the triangulation was not finished and the author worked long hours computing in order to finish a report and then get out in the field. His coworkers had already left for the northwest of Iceland where they would spend the summer and where he wanted to be, but engineers needed the results of the surveying at Búrfell during the summer.

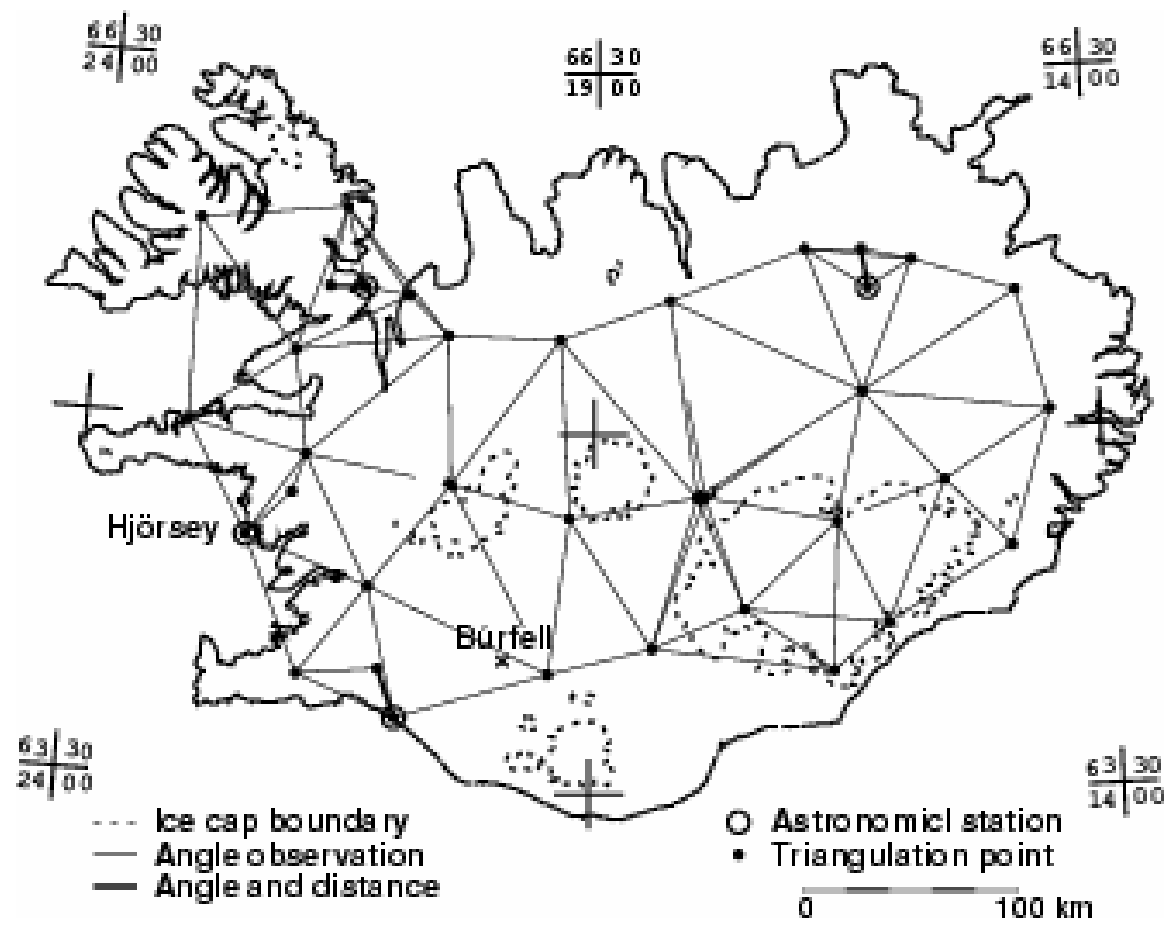

Fig. 1. Observations in the first order triangulation network in Iceland were made in 1955-56 by Geodætisk Institut of Denmark with the assistance of the National Land Survey of Iceland. The network adjustment took place in Denmark. The Hjörsey geodetic datum of 1955, named after an astronomical station in the network, was used by surveyors working in the latter half of the 20th century. Búrfell is the site of a hydro power plant built in 1966-69.

The author used an electromechanical calculator, pen, and paper for the calculations. The repetitive nature of the task, but especially the author's wish to be elsewhere, made him seriously consider its future automation by means of an electronic computer.

\subsection{Background}

The geoid is a property of the gravity field of the earth [9]. At sea, it roughly coincides with mean sea level. The Hayford reference ellipsoid used in the Hjörsey geodetic datum has a standard form, but its location and orientation were determined 
mainly by astronomical observations in 1955 , to approximate the geoid locally in the region of Iceland. After Danish surveyors established the first order network, Icelandic surveyors, when computing in the Hjörsey geodetic datum, assumed that the local normal to the ellipsoid and the local vertical axis at a point coincide.

When observing at a triangulation point (the station), where a theodolite has been set up, centered and leveled, the observer can rotate the upper part of the theodolite with the telescope about the vertical axis, but the lower part contains the horizontal circle at rest in the horizontal plane of the station.

A triangulation network has triangulation points and lines of sight joining them in three dimensions. Each point of the network, a triangulation point or a point on a line of sight, is projected along the local normal onto the surface of the ellipsoid, where a second network is produced. The surface of the ellipsoid is projected by means of a mathematical formula, Lambert's conformal conical projection, onto the projection plane, where a third network is created. The images of the lines of sight are curves and the observed horizontal angles (in the first network) are reproduced unchanged as angles between (tangents to) these curves. Since this is complicated, geodesists prefered to replace the curves with straight lines and a fourth and final network is created. From the actual observations in the three-dimensional network and approximate coordinates in this fourth network, geodesists have deduced formulas for computing the so-called reduced observations which may be treated as if they were observations made in the two-dimensional space of the projection plane.

\subsection{Field Work}

The fieldwork culminated in observations of horizontal angles at the triangulation points. A simplified description of the observations at a station is to say that the field operator aimed the theodolite at the targets (the distant triangulation points) in clockwise order and

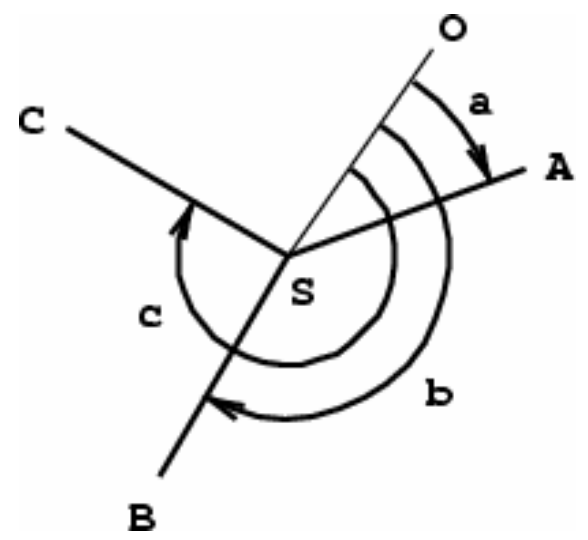

Fig. 2. The horizontal plane at triangulation point $S$ : Triangulation points $A, B$, and $C$ are observable targets. The lines of sight are projected vertically onto the horizontal plane where they meet the horizontal circle (at rest during observations) in graduations or numbers $\mathrm{a}, \mathrm{b}$, and $\mathrm{c}$. The line SO passes through zero on the horizontal circle. The numbers a, b, and $\mathrm{c}$ are recorded in the field book. They are a set of direction readings. In this case, the number of targets, which must be less than eight, is three. 
read the horizontal circle each time. (In fact, we repeated this twelve times and then computed the means). This gave one set of direction readings (see Figure 2). By this method of observation adjacent angles $(b-a$ and $c-b$ in Figure 2) are correlated but the direction readings are not. To observe the adjacent angles in an uncorrelated manner would require a more complicated procedure of observations in the field.

\subsection{Office Work}

The most time consuming part of the office work was adjustment of observations. In adjustment of indirect observations [8] in a triangulation network, the horizontal coordinates of the unknown points are to be determined in a way that minimizes the sum of squares of observation residues. We previously computed the heights above the reference ellipsoid of all points in the network and during the adjustment considered the heights known. The author used this variant of adjustment in the computation of the horizontal coordinates of triangulation points at Búrfell.

We computed the initial coordinates for the unknown points, usually by forward section from two known or already computed points. Denoting the initial coordinates of point $\mathrm{P}_{\mathrm{i}}$ by $\left(\mathrm{X}_{\mathrm{i}}, \mathrm{Y}_{\mathrm{i}}\right)$, they would later become $\left(\mathrm{X}_{\mathrm{i}}+\mathrm{x}_{\mathrm{i}}, \mathrm{Y}_{\mathrm{i}}+\mathrm{y}_{\mathrm{i}}\right)$, where $\mathrm{x}_{\mathrm{i}}$ and $\mathrm{y}_{\mathrm{i}}$ are coordinate changes to be found by adjustment. In this initial network, with some points with known coordinates and unknown points with initial coordinates, distances and directions were carefully computed.

We reduced each observation so that the reduced observation became as if we had made it in the straight-edged network in the plane. These reductions were made using precomputed tables and diagrams. The reductions take into account the curvature of the

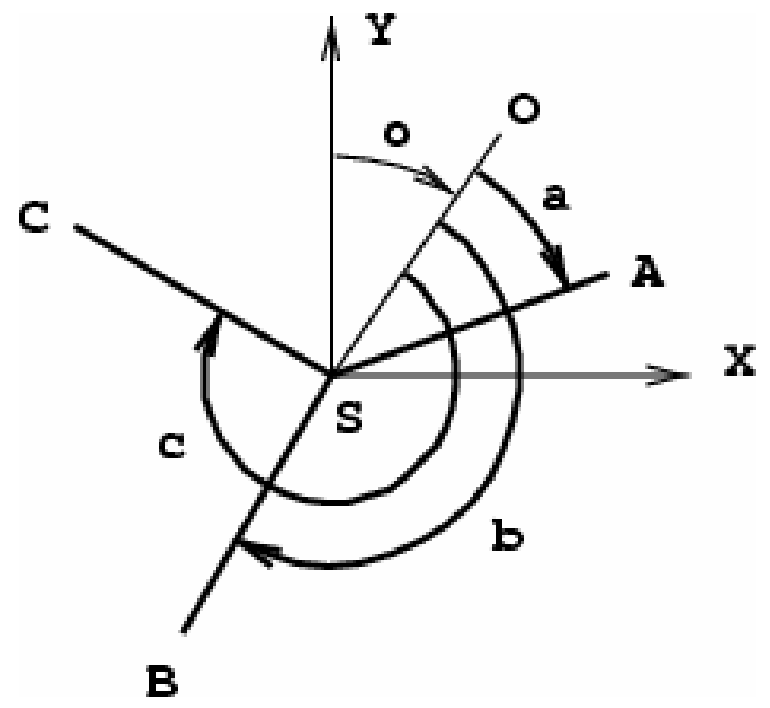

Fig. 3. The projection plane: $S$ is the image of a station joined by straight lines to the images of targets A, B, and C. Line SO passes through zero on the image of the horizontal circle. Angles $\mathrm{a}, \mathrm{b}$, and $\mathrm{c}$ are reduced observations. The unknown angle $\mathrm{o}$, clockwise from the $\mathrm{Y}$-axis to the line $\mathrm{SO}$, is named orientation constant. The observed direction angles or directions to the targets are $\mathrm{o}+\mathrm{a}, \mathrm{o}+\mathrm{b}$, and $\mathrm{o}+\mathrm{c}$. 
earth and the distortion due to Lambert's conformal conical projection onto the plane and, in the case of distance between two points, the different heights of the points above the Hayford reference ellipsoid. (However, we observed no distance at Búrfell).

The expression atan $2\left(\mathrm{X}_{\mathrm{i}}+\mathrm{x}_{\mathrm{i}}-\mathrm{X}_{0}-\mathrm{x}_{0}, \mathrm{Y}_{\mathrm{i}}+\mathrm{y}_{\mathrm{i}}-\mathrm{Y}_{0}-\mathrm{y}_{0}\right)$ holds for the angle at station $\mathrm{P}_{0}$ clockwise from the $\mathrm{Y}$-axis to the line joining $\mathrm{P}_{0}$ to $\operatorname{target} \mathrm{P}_{\mathrm{i}}$. With the help of Figure 3 this direction angle for the line joining station to target can be expressed differently, resulting in an observation equation, loosely formulated as "observation constant + reduced direction reading + residue $=$ arctangent function". The arctangent function has to be linearized by Taylor's expansion before being used in linear equations.

Each of the $m$ observation equations in a set of $m$ direction readings contains an unknown orientation constant and a residue, but the orientation constant does not occur in other equations. It is easy to prove by the method of least squares, that the sum of the $m$ residues is zero, and an equation created by summing the $m$ observation equations is free of residues. We could use this equation in at least two different ways for eliminating the orientation constant from the observation equations. In Method 1, the orientation constant is eliminated from the equations by subtracting the mean of the $m$ equations from each of the equations, but the number of unknown variables in each observation equation is thereby increased. In Method 2, the orientation constant is deleted from each of the $m$ observation equations and the truncated equations used with weight 1 , provided the equation formed by summing the $m$ truncated equations is used with weight $-1 / m$ when the normal equations are formed. This gives the same normal equations as Method 1. See "Schreibersche Summengleichung" in [10].

The first stage of the adjustment at Búrfell involved six unknowns and four known triangulation points. We used a precision of eight decimal digits when computing distances, directions, and coordinates in the initial network, but four or five digits in the following matrix computations. We used Method 2 and a simulation shows that we needed 1440 multiplications and divisions for the matrix computations. For simplification, we show the use of Method 1 (requiring 2310 multiplications and divisions) in the following discussion.

We can write the observation equations for the whole network in matrix notation as $\boldsymbol{v}=\boldsymbol{B} \boldsymbol{x}-\boldsymbol{r}$. Here $\boldsymbol{v}$ is a vector of unknown residues, $\boldsymbol{r}$ is a constant vector, $\boldsymbol{x}$ is an unknown vector of changes to the initial coordinates of unknown points, and $\boldsymbol{B}$ is a matrix of rows as many as there are observations; and columns as many as there are unknown coordinates. The vector $\boldsymbol{r}$ has a component in the column space of $\boldsymbol{B}$ and a component orthogonal to that space, hence $\boldsymbol{v}$ is least when it is equal to the latter component and its component in the column space of $\boldsymbol{B}$ is zero, which means that $\boldsymbol{B}^{T} \boldsymbol{v}=\mathbf{0}$. The normal equations $\boldsymbol{B}^{T} \boldsymbol{B} \boldsymbol{v}=\boldsymbol{B}^{T} \boldsymbol{r}$ follow. We need to compute the upper triangular part of $\boldsymbol{B}^{T} \boldsymbol{B} \boldsymbol{v}$ and the right hand side vector $\boldsymbol{B}^{T} \boldsymbol{r}$.

By its form the normal equation matrix is positive semidefinite and it will be positive definite if regular. We can infer some properties of the matrix from the network from which it is computed. The matrix may be singular if the surveyor forgets to make observations in some part of the network. It will be regular if no part of the network could move relative to the rest without contradicting observations. The normal equations were solved by Gaussian elimination [4]. 


\section{A Computer Program for the Adjustment}

In December 1964, an IBM 1620 Model II computer became available at the Computing Center of the University of Iceland [7] and in 1965, the author wrote a FORTRAN II program for adjustment of triangulation using adjustment of indirect observations. At first, the computer was without removable disk and without a printer. Input, output, and even external storage had to be on punched cards (named IBM cards) and FORTRAN II used statement numbers in its branching and looping statements that could easily have resulted in "spaghetti code".

We could do the adjustment in one or more stages in one computer run. The input to the program was on punched cards and consisted of a dictionary stack, one observations stack for each stage of adjustment, and a coordinates stack. The dictionary stack was used for translating point names into point numbers, an observations stack contained observations for one stage of adjustment and instructions for the initialization of coordinates of unknown points, and the coordinates stack contained a list of points with or without coordinates.

At each stage of adjustment, we could use a chain of triangles, specified on a punched card, to direct the computation of coordinates of unknown points. Each triangle contained at least two observed angles and each chain at least two points known initially or from the adjustment in a previous stage. Alternatively, we could use a card with a sequence of point names to direct a special routine to compute the coordinates of each of the points by resection. We used the formulation in Handbuch der Vermessungskunde for the reduction of observations to the plane [5].

The observation equations for each set of direction readings were formed as explained in the previous section. They were not stored but used to compute their contribution to the normal equations. If any residues were outside specified bounds, the program reported all such residues and the processing stopped.

We solved the normal equations by Cholesky factorization [4]. We computed the elements of the diagonal and super-diagonal of the inverse of the normal equation matrix (but not the entire inverse matrix) and they were used for computing mean errors of coordinates and the parameters of error ellipses and confidence ellipses for the unknown points [8].

The program consisted of a small main program and five subroutines running one after another, each invoking a number of other subroutines and using the COMMON declaration (i.e. global data) for data storage. We used this structure to maximize storage space for the normal equations and we implemented vectors and matrices as one-dimensional arrays. The first version of the program was about 2100 lines of code.

\section{Adjustment Using the Computer}

The use of the program changed the work of the surveyor by enabling him to plan larger networks or have larger parts (up to 23 unknown points) of a network adjusted as one whole, and he could spend more time in the field and less time in the office.

At Orkustofnun there was access to a card punch machine where the data was entered into white IBM cards. We then brought the cards to the Computing Center at 
the University where computer operators kept the program on differently colored cards. A stack of cards with the first part of the program was put in front of the input cards in the input card hopper, the program started, and cards with intermediate results appeared in the output card stacker. An operator then put these after the second part of the program in the input card hopper, and so forth. The juggling of card stacks became rather complicated if the adjustment was in many stages. We would then take the final output cards to the Skýrr computing center elsewhere in Reykjavík where an operator used an IBM 1401 computer to print their content [1].

\section{Later Improvements}

The first version of the program did not accept observations of distance, but subsequent versions did. By then the Computer Center had added removable data storage disks and a printer to its computer system; as a result, the juggling of card stacks or trips to the second computer were no longer necessary. Later versions of the program used heights above the reference ellipsoid and a three-dimensional model avoiding reductions to the plane, the normal equation matrix was stored as a variable-band matrix, and free adjustment [6] was possible.

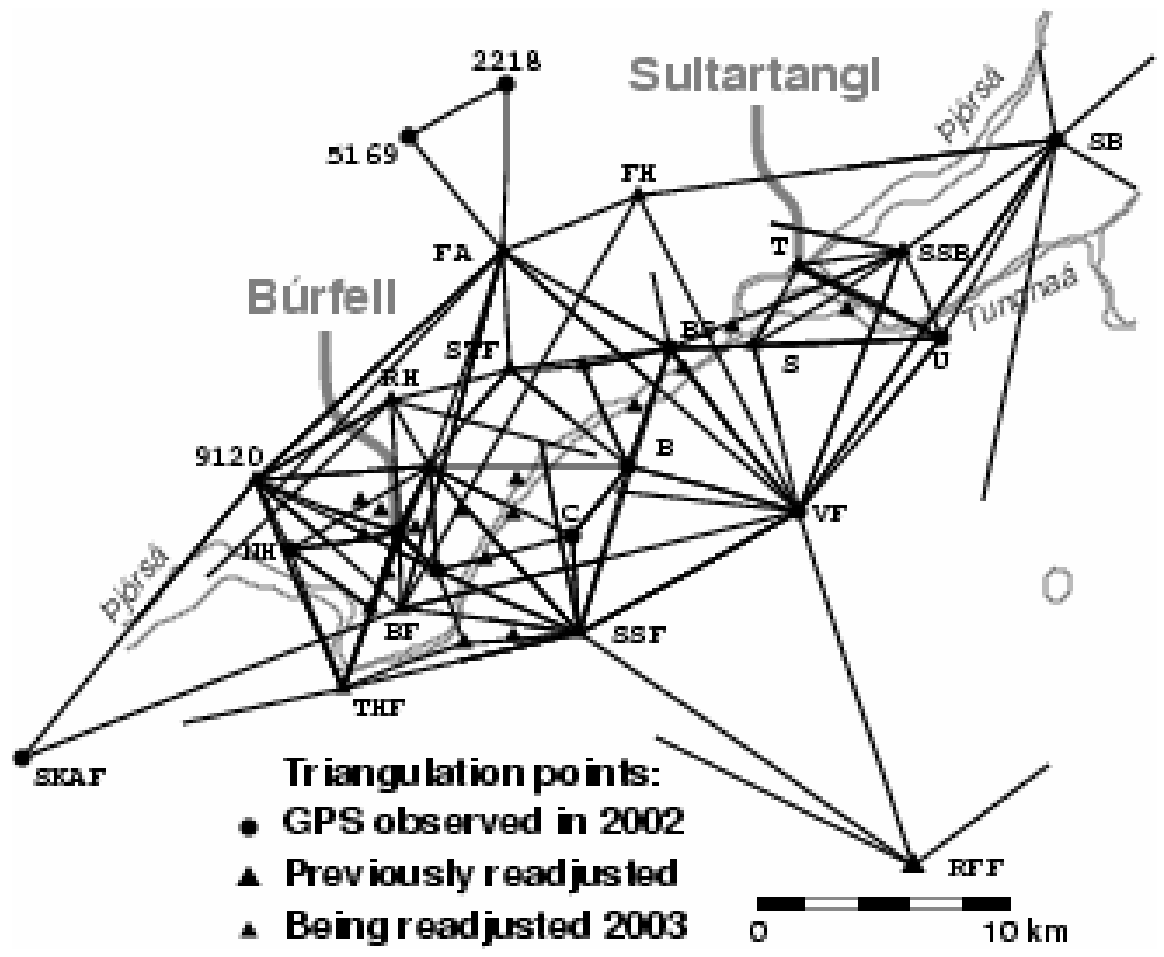

Fig. 4. In 2003, the 40-year-old triangulation in Búrfell area was readjusted with some of the triangulation points fixed by GPS observations. Of the five hydro power plants in the PjórsáTungnaá river system, the 270 MW plant at Búrfell was built in the years 1966-1969 and the 130 MW plant at Sultartangi in 1997-2000. 
We used this program as late as 2003 for re-computing old triangulation networks with some of their points positioned by GPS observations (see Figure 4). By then the computer era had revolutionized land surveying, partly by computers embedded in surveying instruments, and with new technologies such as the Global Positioning System. In the earlier years, triangulation had been greatly facilitated; finally, it became almost obsolete.

\section{Acknowledgements}

My thanks go to Oddur Benediktsson for his help and encouragement and to Bragi Thorbergsson and the editors for their careful reading of the English text.

\section{References}

[1] Benediktsson, O., Gunnarsson, J., Hreinsson, E.B., Jakobsson, J., Kaldalóns, Ö., Kjartansson, Ó., Rósmundsson, Ó., Sigvaldason, H., Stefánsson, G., Zophoniasson, J.: Computerisation of the Icelandic State and Municipalities: 1964 to 1985. In: Bubenko Jr., J., Impagliazzo, J., Sølvberg, A. (eds.) History of Nordic computing: IFIP WG9.7 first working conference on the history of nordic computing (HiNC1), Trondheim, Norway, June 16-18, 2005. Springer, Heidelberg (2005)

[2] Böðvarsson, Á.: Greinargerð frá Landmælingum Íslands. Tímarit Verkfræðingafélags Íslands 2.-3., 56. árg (1971); A report from the National Land Survey of Iceland. Journal of the Association of Chartered Engineers of Iceland 56(2-3), 18-21 (1971)

[3] Böđvarsson, Á.: Landmælingar og kortagerð Dana á Íslandi. Upphaf Landmælinga Íslands, Landmælingar Íslands, Surveying and mapping of the Danish in Iceland. The beginning of the National Land Survey of Iceland. The National Survey of Iceland. Reykjavík, 1996 (in Icelandic)

[4] Duff, I.S., Erisman, A.M., Reid, J.K.: Direct methods for sparse matrices. Clarendon press, Oxford (1989)

[5] Kneissl, M.: Die Längen- und Richtungsreduktion bei der konformen Kegelprojektion. In: Jordan, W., Eggert, O., Kneissl, M. (eds.) Handbuch der Vermessungskunde, Band IV, Zweite hälfte, Stuttgart, pp. 841-844 (1959) (in German)

[6] Koch, K.-R.: Parameterschätzung und Hypothesentests in linearen Modellen. Ferd. Dümmlers Verlag, Bonn (1980) (in German)

[7] Magnússon, M.: The Advent of the first General Purpose Computer in Iceland and its Impact on Science and Engineering. In: Bubenko Jr., J., Impagliazzo, J., Sølvberg, A. (eds.) History of Nordic computing: IFIP WG9.7 first working conference on the history of nordic computing (HiNC1), June 16-18, 2005. Springer, Heidelberg (2005)

[8] Mikhail, E.: Observations and Least Squares. Dun-Donnelley, New York (1976)

[9] Torge, W.: Geodesy, 2nd edn. Walter de Gruyter, Berlin (1991)

[10] Wolf, H.: Ausgleichungsrechnung. Formeln zur praktischen Anvendungen, p. 143. Ferd. Dümmlers Verlag, Bonn (1975) (in German) 